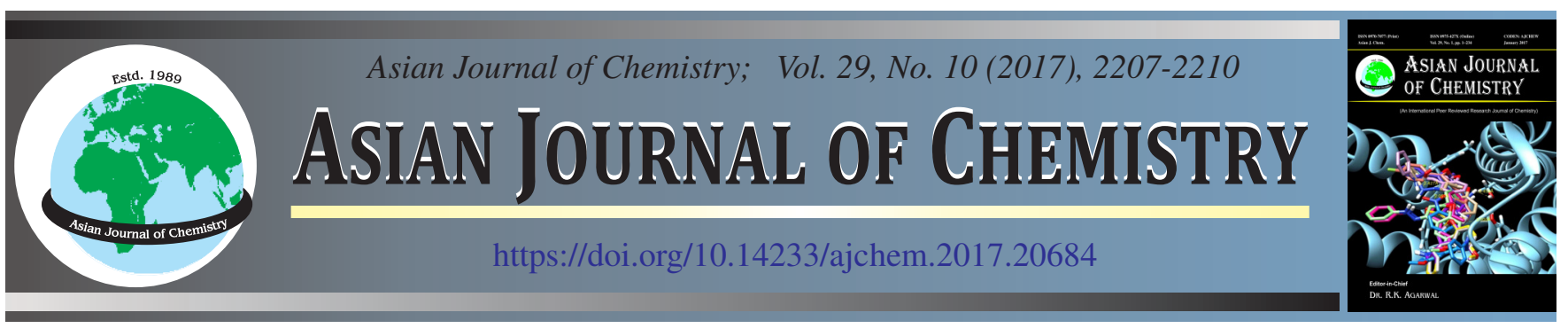

\title{
Thermal Stability on Morphology and Crystal Structures of Hydrothermally Synthesized Titanate Nanotubes and Their Photocatalytic Activity
}

\author{
Mohd Hasmizam Razali ${ }^{1,2, *}$, Uwaisulqarni M. Osman ${ }^{2}$, Mohd Zul Helmi Mohd Rozaini ${ }^{3}$ and Mahani Yusoff ${ }^{4}$
}

${ }^{1}$ Advanced Nanomaterials Research Group, School of Fundamental Sciences, Universiti Malaysia Terengganu, 21030 Kuala Terengganu, Terengganu, Malaysia

${ }^{2}$ School of Fundamental Sciences, Universiti Malaysia Terengganu, 21030 Kuala Terengganu, Terengganu, Malaysia

${ }^{3}$ Institute of Biotechnology Marine, Universiti Malaysia Terengganu, 21030 Kuala Terengganu, Terengganu, Malaysia

${ }^{4}$ Faculty of Bioengineering and Technology, Universiti Malaysia Kelantan Kampus Jeli, Karung Berkunci No.100, 17600 Jeli, Kelantan, Malaysia

*Corresponding author: Fax : +60 9 6694660; Tel : +609 6683783; E-mail: mdhasmizam@umt.edu.my

\section{INTRODUCTION}

Nowadays, nanostructured titania and titanate materials have been widely studied due to their multi-function properties. In particular, titanate nanotubes have received a great deal of attention because of large surface area that leads to a wide variety of applications, including secondary lithium batteries, dye sensitized solar cells, catalysts and bio-composite [1-6]. Titanate nanotubes have also been tested for use as photocatalysts in heterogeneous photodegradation and have shown excellent performance for degrading textile dyes, which makes them very important ecomaterials [7]. The exploitation of this material in the photochemical and sensor are also appears promising [8-10]. However, high temperature within the range of $100-700{ }^{\circ} \mathrm{C}$ are necessary in these applications, for example, for oxygen sensors in car exhaust management. Therefore, the investigation on the thermal stability of synthesized titanate nanotubes on crystal structure and morphological properties is importance in order to retain their performance activity. This is interesting subject for new investigations in order to further elucidate the nature and the thermally induced structural transition and morphological evolution of this material. Thus, this paper study the thermal stability on morphology and crystal structure of sodium titanate nanotube synthesis using simple hydrothermal method. The hydrothermal method was used in this study since this technique has shown many advantages such as simple equipment requirements, mild reaction conditions, less energy consumption and a large number of variable factors to control sample morphology [11]. Hydrothermal reactions can be classified as any heterogeneous chemical reaction in the presence of a solvent (aqueous and non-aqueous) carried out under controlled temperature and pressure in a closed system. For many years it was believed that the pressure must be greater than $1 \mathrm{~atm}$ and temperatures greater than $100{ }^{\circ} \mathrm{C}$ to classify a reaction as hydrothermal [12].

\section{EXPERIMENTAL}

General procedure: $2.0 \mathrm{~g}$ of commercial $\mathrm{TiO}_{2}$ powder precursor (Merck) was dispersed in $10 \mathrm{M} \mathrm{NaOH}(100 \mathrm{~mL})$ with constant stirring for $30 \mathrm{~min}$. The mixture was transferred into Teflon vessel and subjected to hydrothermal treatment at $150{ }^{\circ} \mathrm{C}$ for $24 \mathrm{~h}$ in autoclave. When the reaction was completed, the white solid precipitate was collected and dispersed into $0.1 \mathrm{M} \mathrm{HCl}(200 \mathrm{~mL})$ with continuous stirring for $0.5 \mathrm{~h}$ for washing. Then, the washing was followed by distilled water 
until the $\mathrm{pH} 12$ of washing solution was obtained. The precipitate was collected through filtration and subsequently dried at $80{ }^{\circ} \mathrm{C}$ for $24 \mathrm{~h}$ in an oven. In order to study the thermal stability, products were calcined at 300, 400, 500, 600 and $700{ }^{\circ} \mathrm{C}$ for $2 \mathrm{~h}$ in furnace.

Detection method: The crystal structure was studied using X-ray diffraction (XRD), Bruker D8 diffractometer with $\mathrm{Cu}-\mathrm{K}_{\alpha}(\lambda=1.54021 \AA)$ and scans were performed in step of $0.2^{\circ} \mathrm{s}$ over the range of $2 \theta$ from 10 up to $90^{\circ}$. Raman spectroscopy was carried out at room temperature using a Horiba Jobin-Yvon HR800 UV Raman spectrometer. The morphology of samples was observed via FESEM and TEM using ZEISS SUPRA $^{\mathrm{TM}}$ 35VP FESEM and Philips CM12 TEM, respectively. The photocatalytic degradation experiment was carried out by adding $0.1 \mathrm{~g}$ of samples into $100 \mathrm{~mL}$ of $20 \mathrm{ppm}$ methyl orange dye solution. The suspension was subjected to UV irradiation for $3 \mathrm{~h}$. The UV light source was provided by an UV bench lamp (302 nm, $230 \mathrm{~V} \sim 50 \mathrm{~Hz})$. The aqueous suspension was magnetically stirred throughout the experiment. At every $30 \mathrm{~min}$ of time intervals $5 \mathrm{~mL}$ of aliquot was taken out using syringe and then filtered through $0.45 \mu \mathrm{m}$ Millipore syringe filter. Then absorption spectra were recorded via UVvisible spectrophotometer (Perkin Elmer Lambda 35 UV-Vis) and the percentage of methyl orange degradation was calculated using the formula in eqn. 1.

$$
\text { Degradation }(\%)=\frac{\mathrm{C}_{0}-\mathrm{C}_{\mathrm{t}}}{\mathrm{C}_{0}} \times 100
$$

where $\mathrm{C}_{0}$ is the initial absorption of dye and $\mathrm{C}_{\mathrm{t}}$ is the absorption of dye after the reaction at ' $t$ ' time.

\section{RESULTS AND DISCUSSION}

X-ray diffraction pattern of samples that were calcined at different temperature is shown in Fig. 1. After calcination at 300,400 and $500^{\circ} \mathrm{C}$, the samples exhibit similar pattern which is identical to sodium trititanate (Fig. 1a-c). This was similarly observed and reported by Lan et al. [13] and Ribbens et al. [14]. Similar XRD patterns suggested that the crystallographic structure of the samples were stable up to $500^{\circ} \mathrm{C}$. It could be ascribed to the interlayer spacing typical for one-dimensional titanate structure [14]. Upon calcination at 600 and $700{ }^{\circ} \mathrm{C}$, emergence of sharp and narrow peaks took place indicating that the crystallinity of the sample had increased. These new peaks can be assigned to sodium hexatitanate and titaniaanatase (Fig. 1d and 1e) $[15,16]$. The presence of sodium hexatitanates phase after calcination is a crucial phenomenon in understanding the structural properties of titanate nanostructures. At higher calcination temperatures sodium trititanates undergo dimerization like process leading to the formation of sodium hexatitanates. Dimerization is the process by which two molecules of the same chemical composition form a condensation product [17].

The difference in the structures of sodium trititanates and sodium hexatitanates is that the former presents a lamellar structure with $\mathrm{Ti}_{3} \mathrm{O}_{7}{ }^{2-}$ corrugated layers and two interlamellar $\mathrm{Na}^{+}$ions [18]. Sauvet et al. [19] proposed that at higher temperatures sodium trititanates tend to fuse and the formation of $\mathrm{Na}_{2} \mathrm{Ti}_{6} \mathrm{O}_{13}$ is the result of "dimerization like" process of

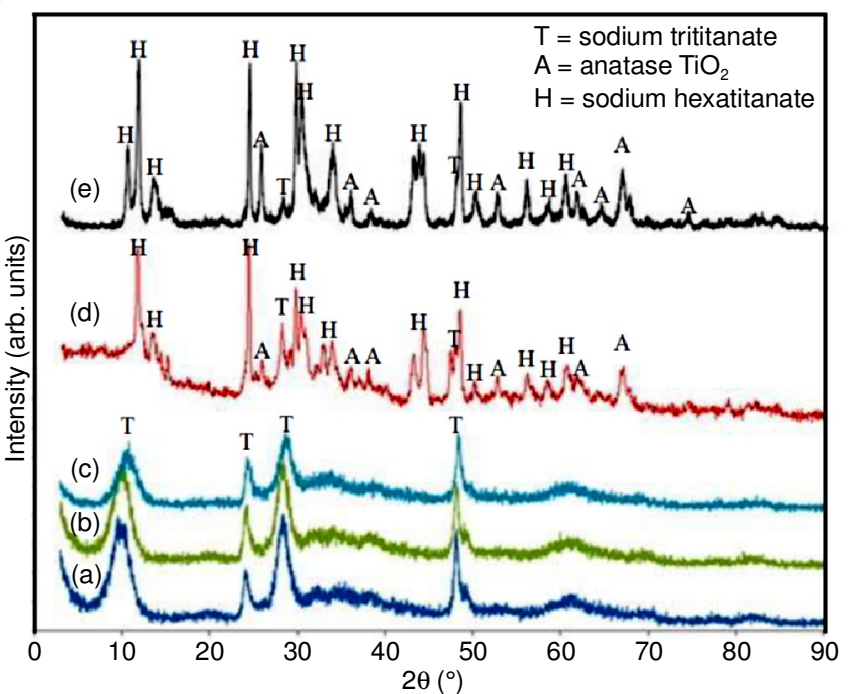

Fig. 1. XRD pattern of the samples calcined at (a) $300{ }^{\circ} \mathrm{C}$ (b) $400{ }^{\circ} \mathrm{C}$ (c) $500{ }^{\circ} \mathrm{C}$ (d) $600{ }^{\circ} \mathrm{C}$ (e) $700{ }^{\circ} \mathrm{C}$ for $2 \mathrm{~h}$

$\mathrm{Na}_{2} \mathrm{Ti}_{3} \mathrm{O}_{7}$. The presence of $\mathrm{Na}_{2} \mathrm{Ti}_{6} \mathrm{O}_{13}$ in the thermal products can be considered as strong evidence that the structure and composition of titanate compound and a general formula may be assigned as $\mathrm{Na}_{2-\mathrm{x}} \mathrm{H}_{\mathrm{x}} \mathrm{Ti}_{3} \mathrm{O}_{7}$.

Fig. 2 displays the Raman spectra of samples calcined at various temperatures. Calcination at 300,400 and $500{ }^{\circ} \mathrm{C}$, Raman spectra recorded similar patterns, whereby the peaks at about 280 and $446 \mathrm{~cm}^{-1}$ appeared (Fig. 1a-c). The broad peak at $280 \mathrm{~cm}^{-1}$ is characteristic to phonon mode of titanate layered structures and assigned to the symmetric stretching of a short Ti-O [20]. While, the peak at $446 \mathrm{~cm}^{-1}$ belong to the Ti$\mathrm{O}$ bending vibration involving six-coordinated titanium atoms and three coordinated oxygen atoms [21]. After calcination up to $700{ }^{\circ} \mathrm{C}$, peaks at 280 and $446 \mathrm{~cm}^{-1}$ could still be observed and new peaks appeared at about 145, 197, 223, 304, 346, 411,675 and $884 \mathrm{~cm}^{-1}$ (Fig. 1d) suggesting that the trititanate and hexatitanate structures as well as anatase $\mathrm{TiO}_{2}$. The Raman analysis is in line with the XRD results.

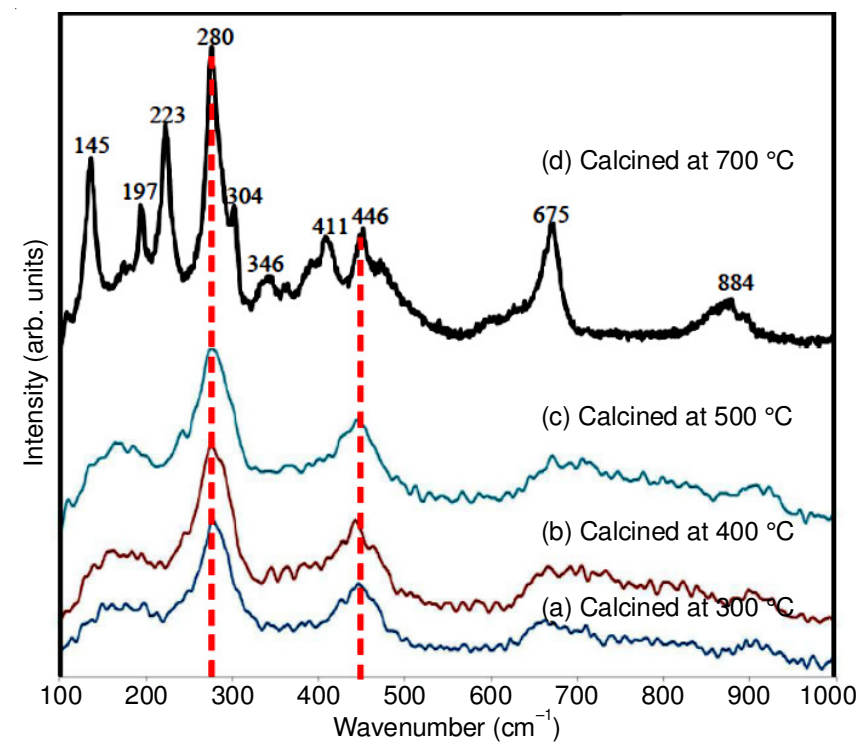

Fig. 2. Raman spectra of the samples calcinedat (a) $300{ }^{\circ} \mathrm{C}$ (b) $400{ }^{\circ} \mathrm{C}$ (d) $500{ }^{\circ} \mathrm{C}$ (e) $700{ }^{\circ} \mathrm{C}$ for $2 \mathrm{~h}$ 
The FESEM micrographs of sample after calcination at various temperatures are shown in Fig. 3. After calcination at 300,400 and $500{ }^{\circ} \mathrm{C}$ for $2 \mathrm{~h}$, similar surface morphology was observed showing the formation of fibrous-like structure with the diameter about $10 \mathrm{~nm}$ and several hundred nanometers in length (Fig. 3a-c). However at $600{ }^{\circ} \mathrm{C}$, the sample had changed significantly with a mix of fibrous-like structure as well as large and short rod-like particles on the top surface (Fig. 3d). As the calcination temperature was increased to $700{ }^{\circ} \mathrm{C}$, only enlarge nanorods structure were observed (Fig. 3e), indicates that the morphological transformation occurs. Further study on the morphological transformation was investigated by TEM.

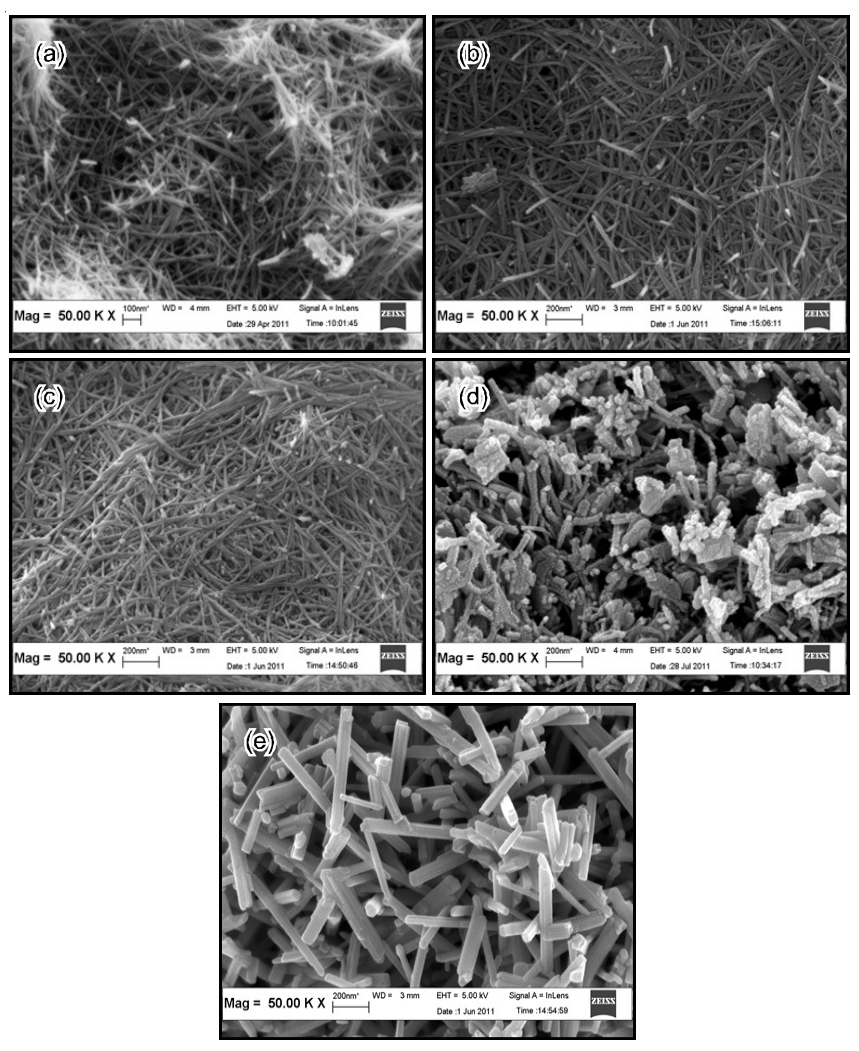

Fig. 3. Raman spectra of the samples calcinedat (a) $300{ }^{\circ} \mathrm{C}$ (b) $400{ }^{\circ} \mathrm{C}$ (d) $500{ }^{\circ} \mathrm{C}$ (e) $700{ }^{\circ} \mathrm{C}$ for $2 \mathrm{~h}$

TEM observation of the samples calcined at 300, 400 and $500{ }^{\circ} \mathrm{C}$, revealed hollow fibers thus verifying the formation of nanotubes structure as shown in Fig. 4a-c, respectively. The result also suggests that the nanotubes structure were thermally stable up to $500{ }^{\circ} \mathrm{C}$. However, when the calcination temperature was increased to $600{ }^{\circ} \mathrm{C}$, nanorods started to form the film (Fig. 4d) and at $700{ }^{\circ} \mathrm{C}$, only nanorods were obtained (Fig. 4e). This indicates that the nanotubes had completely transformed to nanorods. The nanorods (non-hollow structures) within 65-70 nm in diameter were formed as a result of the mobilizations of $\mathrm{Na}^{+}$ into the nanotubes inner channel as well as the boundary pores among nanotubes and then recrystallized to form nanorods [22].

The photocatalytic activity of the sample after calcination at various temperatures for photodegradation of methyl orange is shown in Fig. 5. The degradation of methyl orange was minimal $(<16 \%)$ in the presence of samples calcined at 300, 400, 500 and $700{ }^{\circ} \mathrm{C}$. This phenomenon is in accordance with the crystal structure as a function of calcination temperature. The sodium

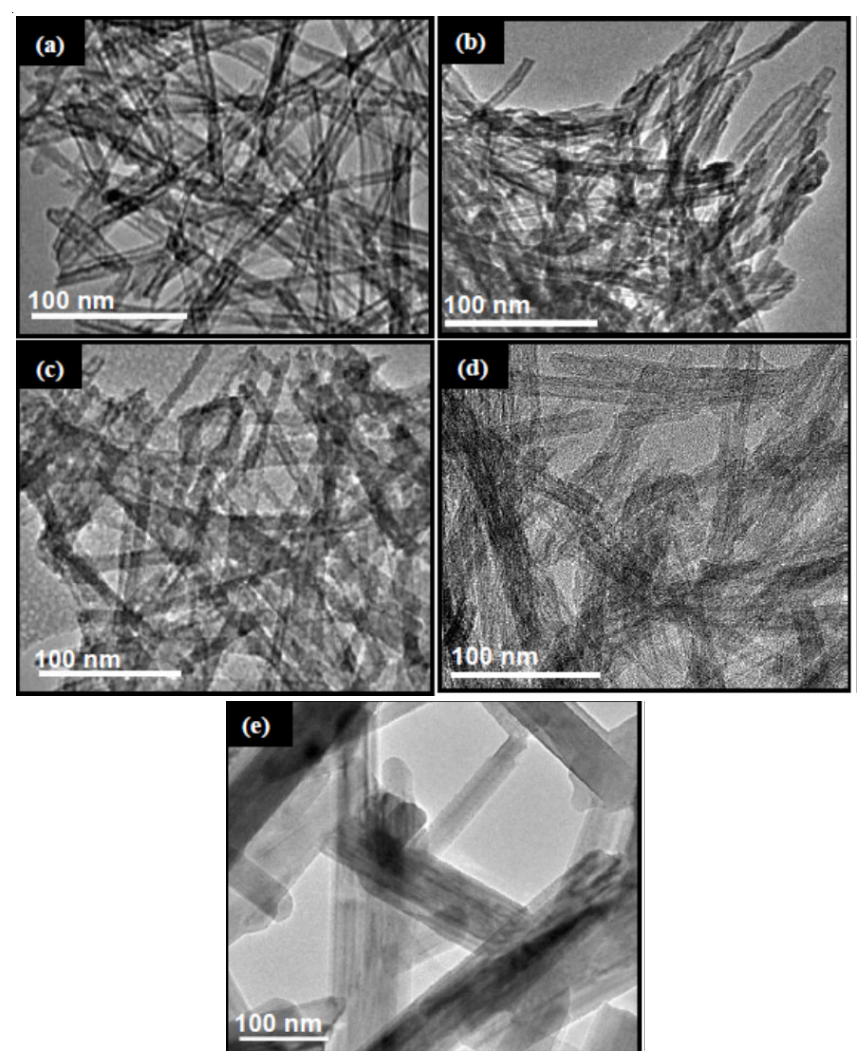

Fig. 4. TEM micrographs of the samples calcined at (a) $300{ }^{\circ} \mathrm{C}$ (b) $400{ }^{\circ} \mathrm{C}$ (c) $500{ }^{\circ} \mathrm{C}$ (d) $600{ }^{\circ} \mathrm{C}$ and (e) $700{ }^{\circ} \mathrm{C}$ for $2 \mathrm{~h}$

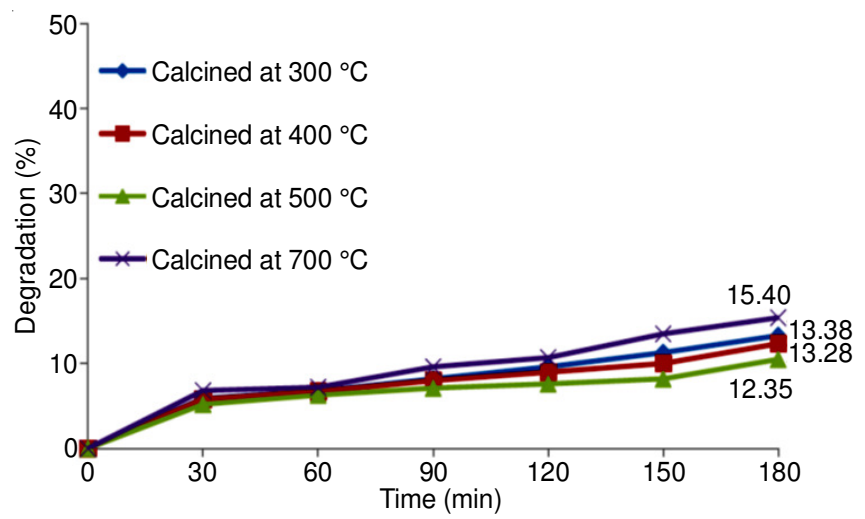

Fig. 5. Photocatalytic degradation of methyl orange in the presence of the samples calcined at (a) $300{ }^{\circ} \mathrm{C}$ (b) $400{ }^{\circ} \mathrm{C}$ (c) $500{ }^{\circ} \mathrm{C}$ (d) $600{ }^{\circ} \mathrm{C}$ and (e) $700{ }^{\circ} \mathrm{C}$ for $2 \mathrm{~h}$

trititanate nanotubes structure remained unchanged until at $500{ }^{\circ} \mathrm{C}$ calcination temperature. At $700{ }^{\circ} \mathrm{C}$, they transformed into sodium hexatitanates and small fraction of anatase $\mathrm{TiO}_{2}$ with some parts still remained as sodium trititanates. Thus, the degradation of methyl orange remained unchanged at low degradation rate because the titanate structure shows low photocatalytic activity, which was similarly suggested by other researchers [17]. In titanate compound there is a structural increase of inter-layered Ti-O bonded [23]. Overload of oxygen in interlayered Ti-O nanotubes can make difficult the transfer of interfacial charges and to accept photoinduced electrons efficiently. This could be a reason for the low of activity in titanate nanotube structures. The small removal of methyl orange for the titatane samples was probably due to adsorption of methyl orange on the nanotubes. 


\section{Conclusion}

The morphology and crystal structure of the sodium trititanate nanotubes thermally stable after calcination at 300, 400 and $500{ }^{\circ} \mathrm{C}$. However, at 600 and $700{ }^{\circ} \mathrm{C}$ calcination temperature, the nanotubes transformed to the nanorods consists a mixture of sodium trititanate, sodium hexatitanate and anatase $\mathrm{TiO}_{2}$. By referring to the degradation of methyl orange, the sodium trititanate nanotubes shows low photocatalytic activity due to their titanate crystal structure. After calcination at various temperature studied also show low photocatalyctic activity because the sodium trititanate thermally stable up to $500{ }^{\circ} \mathrm{C}$. Although after the highest calcination temperature studied at $700{ }^{\circ} \mathrm{C}$, some of the sodium trititanate remains same and the rest transformed to sodium hexatitanate. Only small fraction of anatase $\mathrm{TiO}_{2}$ phase was traced. This had led to the sample to have low photocatalytic activity for degradation of methyl orange.

\section{ACKNOWLEDGEMENTS}

The authors are grateful to Universiti Malaysia Terengganu (UMT) for providing the facilities to carry out this project and Ministry of Higher Education of Malaysia for the financial support vote FRGS 59358.

\section{REFERENCES}

1. P. Zhang, Y. Huang, W. Jia, Y. Cai, X. Wang, Y. Guo, D. Jia, Z. Sun and Z. Guo, Electrochim. Acta, 210, 935 (2016); https://doi.org/10.1016/j.electacta.2016.06.017.

2. L. Zhao, J. Yu, J. Fan, P. Zhai and S. Wang, Electrochem. Commun., 11, 2052 (2009);

https://doi.org/10.1016/j.elecom.2009.08.050.

3. X. Badema and K. Cho, J. Ind. Eng. Chem., 29, 32 (2015); https://doi.org/10.1016/i.jiec.2015.03.027.

4. N.M. Dos Santos, J.M. Rocha, J.M.E. Matos, O.P. Ferreira, J.M. Filho, B.C. Viana and A.C. Oliveira, Appl. Catal. A, 454, 74 (2013); https://doi.org/10.1016/j.apcata.2012.12.035.

5. J. Yu and H. Yu, Mater. Chem. Phys., 100, 507 (2006); https://doi.org/10.1016/j.matchemphys.2006.02.002.

6. D. Emadzadeh, W.J. Lau, M. Rahbari-Sisakht, H. Ilbeygi, D. Rana, T. Matsuura and A.F. Ismail, Chem. Eng. J., 281, 243 (2015); https://doi.org/10.1016/j.cej.2015.06.035
7. B. Barrocas, C.D. Nunes, M.L. Carvalho and O.C. Monteiro, Appl. Surf. Sci., 385, 18 (2016); https://doi.org/10.1016/j.apsusc.2016.05.080.

8. E.M. Neville, J.M.D. MacElroy, K.R. Thampi and J.A. Sullivan, J. Photochem. Photobiol. Chem., 267, 17 (2013); https://doi.org/10.1016/i.jphotochem.2013.06.008.

9. D.U. Hong, C.-H. Han, S.H. Park, I.-J. Kim, J. Gwak, S.-D. Han and H.J. Kim, Curr. Appl. Phys., 9, 172 (2009); https://doi.org/10.1016/j.cap.2008.01.010.

10. D. Liu, T. Liu, C. Lv and W. Zeng, Mater Sci: Mater Electron, 23, 576 (2012); https://doi.org/10.1007/s10854-011-0443-5.

11. H. Li, X. Shen, Y. Liu, L. Wang, J. Lei and J. Zhang, J. Alloys Compd., 687, 927 (2016); https://doi.org/10.1016/j.jallcom.2016.05.320.

12. K. Byrappa and M. Yoshimura, Handbook of Hydrothermal Technology, Noyes Publications, New Jersey, USA (2001).

13. Y. Lan, X.P. Gao, H.Y. Zhu, Z.F. Zheng, T.Y. Yan, F. Wu, S.P. Ringer and D.Y. Song, Adv. Funct. Mater., 15, 1310 (2005); https://doi.org/10.1002/adfm.200400353.

14. S. Ribbens, V. Meynen, G.V. Tendeloo, X. Ke, M. Mertens, B.U.W. Maes, P. Cool and E.F. Vansant, Micropor. Mesopor. Mater, 114, 401 (2008); https://doi.org/10.1016/j.micromeso.2008.01.028.

15. E. Morgado Jr., M.A.S. de Abreu, G.T. Moure, B.A. Marinkovic, P.M. Jardim and A.S. Araujo, Mater. Res. Bull., 42, 1748 (2007); https://doi.org/10.1016/j.materresbull.2006.11.020.

16. M. Mojica, F. Méndez and J. Alonso, Molecules, 18, 2243 (2013); https://doi.org/10.3390/molecules18022243.

17. M. Qamar, C.R. Yoon, H.J. Oh, N.H. Lee, K. Park, D.H. Kim, K.S. Lee, W.J. Lee and S.J. Kim, Catal. Today, 131, 3 (2008); https://doi.org/10.1016/j.cattod.2007.10.015.

18. O.V. Yakubovich and V.V. Kireev, Crystallogr. Rep., 48, 24 (2003); https://doi.org/10.1134/1.1541737.

19. A.L. Sauvet, S. Baliteau, C. Lopez and P. Fabry, J. Solid State Chem., 177, 4508 (2004); https://doi.org/10.1016/j.jssc.2004.09.008

20. S.-H. Byeon, S.-O. Lee and H. Kim, J. Solid State Chem., 130, 110 (1997); https://doi.org/10.1006/jssc.1997.7286.

21. R. Ma, K. Fukuda, T. Sasaki, M. Osada and Y. Bando, J. Phys. Chem. B, 109, 6210 (2005); https://doi.org/10.1021/jp044282r.

22. O.P. Ferreira, A.G. Souza Filho, J. Mendes Filho and O.L. Alves, J. Braz. Chem. Soc., 17, 393 (2006); https://doi.org/10.1590/S0103-50532006000200025.

23. V. Rodríguez-González, S. Obregón-Alfaro, L.M. Lozano-Sánchez and S.-W. Lee, J. Mol. Catal. A, 353- 354, 163 (2012); https://doi.org/10.1016/j.molcata.2011.11.020. 